\title{
Genetic variation of wood density components in a radiata pine progeny test located in the south of Chile
}

\author{
Francisco ZAMUdio ${ }^{\mathrm{a} *}$, Philippe RoZENBERG $^{\mathrm{b}}$, Ricardo BAETtig $^{\mathrm{a}}$, Adriana VERGARA ${ }^{\mathrm{a}}$, Marco YAÑEZ ${ }^{\mathrm{a}}$, \\ Carlos GANTZ \\ ${ }^{a}$ Facultad de Ciencias Forestales, Universidad de Talca, PO Box 747, 2 Norte 685, Talca, Chile \\ b INRA Orléans, Unité d'Amélioration, Génétique et Physiologie Forestières, BP 20619 Ardon, 45166 Olivet Cedex, France \\ ${ }^{c}$ Forestal Mininco S.A., Avda. Alemania 751, PO Box 399, Los Angeles, Chile
}

(Received 27 October 2003; accepted 27 July 2004)

\begin{abstract}
This article describes changes in the genetic variation of wood density components with cambial age and their relationship with the within-ring area components. Wood samples from 31 half-sib families of radiata pine were submitted to X-ray densitometry procedures. Traits studied were earlywood (ED) and latewood (LD) density, earlywood (EA) and latewood (LA) area, and latewood proportion (LP). Between rings 2 to 5 (juvenile wood) and 11 to 14 (mature wood), heritability estimates suggest that breeding for increased ED is feasible. Upward selection for ED would also be associated with a phenotypic reduction in EA in juvenile and mature wood. Between rings 6 to 10, the heritability estimates for ED indicate low genetic variation in the transition region. Attempts to increase ED by breeding might not have a significant impact on LD, though this trait showed a moderate genetic control in this region. Any change in ED and LD would have unclear effects on EA and LA, respectively, because of the changing pattern of genetic covariances.
\end{abstract}

wood density / heritability / radiata pine / earlywood / latewood

Résumé - Variabilité génétique de composantes de la densité du bois dans un test de descendances de pin radiata dans le sud du Chili. Cet article décrit l'évolution en fonction de l'age cambial de la variabilité génétique de composantes de la densité intra-cerne et des relations entre ces caractères et des composantes de la surface des cernes. Des échantillons de bois appartenant à 31 familles de demi-frères de pin radiata ont été soumis à une procédure d'analyse microdensitométrique. Les caractères étudiés sont la densité du bois initial (ED) et du bois final (LD), la surface du bois initial (EA) et du bois final (LA) et la proportion de bois final dans le cerne. Entre les cernes 2 à 5 (bois juvénile) et les cernes 11 à 14 (bois adulte), les valeurs estimées d'héritabilité suggèrent qu'il est possible d'augmenter ED génétiquement. Une sélection pour une augmentation de ED entraînerait une diminution phénotypique de EA dans le bois juvénile et le bois adulte. Dans la région de transition représentée par les cernes 6 à 10, les estimations de l'héritabilité montrent peu de variabilité génétique. Des tentatives d'augmenter génétiquement la densité de ED pourraient ne pas avoir d'effet significatif sur LD, même si ce caractère est lui-même moyennement génétiquement contrôlé dans cette zone. Toute modification de ED et LD aurait des effets changeants sur EA et LA en raison des variations de la valeur des covariances génétiques.

densité du bois / héritabilité / pin radiata / bois initial / bois final

\section{INTRODUCTION}

Genetic improvement of radiata pine has been conducted in Chile since the late 70's, mainly by breeding of parents selected for their outstanding growth rate and form, although wood density is considered as the main trait of interest by the forest industry. The number of commercial plantings with specific families (full- and half-sibs) or genotypes (clones) will systematically increase in the future. Site preparation, pruning, and thinning are part of currently and intensively applied silvicultural treatments. Hence, trees from improved genetic stocks will reach harvest volume at a younger age and the proportion of juvenile wood within the stem will increase. In New Zealand, the realized genetic gain in stem straightness and stem diameter growth in radiata pine has already produced an increment of juvenile wood proportion [7].

The properties of juvenile wood as compared to mature wood have been widely discussed. The general viewpoint is that juvenile wood has a lower quality than mature wood, although there are some exceptions depending on the end products. Juvenile wood does not have the same adverse connotation as it formerly did for fiber production since TMP and other methods of pulp manufacture have been developed. In juvenile wood, the lignin content is higher and the cellulose content is

\footnotetext{
*Corresponding author: fzamudio@utalca.cl
} 
lower than in mature wood [42]. In Pinus species, juvenile wood is usually characterized by shorter tracheid length and thinner cell walls than mature wood, and thus often produces lower specific gravity wood. Characteristics of solid wood products also differ depending on whether they are made from juvenile or mature wood; strength varies greatly with cambial age and is closely related to microfibrillar angle as well as to specific gravity. Because of its low strength and instability on drying, juvenile wood is still a problem for most solid wood products [42].

Wood heterogeneity is described as an important defect and uniformity of juvenile wood is usually lower than that of mature wood [40,41]. Therefore, possible consequences of an increase in juvenile wood proportion in the stems of future plantings are a decrease of wood mechanical properties and an increase of wood heterogeneity. The forest managers and the wood processors have to face this challenge. The forest managers may have to accept lower prices for harvested timber. The wood processors may have to optimize processing conditions to achieve a reliable end product performance, which can produce an increment in processing costs and in the price of the end products.

One possible action to diminish some of the negative effects of short rotations on wood quality can be to breed for increased juvenile wood density [27, 35]. Wood uniformity across the stem is sometimes cited as the most important of all wood properties, the most desired by the product managers and the most closely tied to profitability [41]. Hence, it would be desirable that genotypes with improved juvenile wood properties also show a reduced within-tree variation [30]. The breeder needs to consider also the use of silviculture since it influences wood properties variation as well.

Wood density is also often considered the most important single property because of its strong effect on yield and quality of both fibrous and solid wood products $[2,12]$. It is a combination of several characteristics, each of which has a strong inheritance pattern of its own.

Here, we consider that: (1) understanding the inheritance pattern of ring density components may help to define selection strategies aiming to increase the density of juvenile wood and simultaneously reduce the variation of this trait between juvenile and mature wood; (2) breeding for increasing the value of wood density components of selected regions of the stem (in terms of cambial age) will enhance wood uniformity (from pith to bark); (3) thus, a reduction of within-tree heterogeneity has to take into account the genetic variation of within-ring density; (4) for radiata pine in Chile, wood microdensity variation from pith to bark is a good descriptor of within-tree heterogeneity; and (5) to avoid unfavorable correlated responses, the genetic relationships among ring density components and ring area related traits must carefully be assessed.

In a first paper [38], we analyzed the relationship between ring density and ring radial growth. We reported significant changes in genetic control of average ring density (ARD) with cambial age, particularly within the transition zone between juvenile and mature wood. Heritability estimates in the juvenile wood region were high, which is positive for breeding purposes, but pith-to-bark trends in genetic and phenotypic correlations between ARD and radial growth were difficult to inter- pret. Thus it was not possible to use these results to suggest general selection strategies for wood density in the radiata pine breeding program. Here, we report results that describe changes in: (1) the genetic variation of wood density components with cambial age and (2) the relationships among these traits and within-ring area components. Results are based on a decomposition of ring density into its earlywood and latewood components.

\section{MATERIALS AND METHODS}

\subsection{Source of material}

Wood samples used in this study came from a progeny test of radiata pine established with 31 open-pollinated families in the South of Chile by Forestal Mininco S.A. The test site was located near Los Angeles, Bio-Bio province (lat. $37^{\circ} 03^{\prime} 05^{\prime}$ ' S, long. $72^{\circ} 27^{\prime} 20^{\prime}$ ', altitude $122 \mathrm{~m}$ above sea level). The area is flat with a mean annual precipitation of $1100 \mathrm{~mm}$ and a period of 4-5 months of drought. The soil texture is sandy with a good drainage capability. Trees were planted in 1981 at $3 \mathrm{~m} \times 2.5 \mathrm{~m}$ spacing. The experiment was arranged in seven randomized complete blocks and families were established in five-tree row plots. No particular silvicultural treatment was performed before the wood sample collection. The number of surviving trees per family was variable.

\subsection{Wood samples collection}

Between one and two trees per plot were chosen for this study. Selected trees were free of any physical and mechanical damage and did not show any sign of plagues and diseases. Finally, a sample of 317 trees were felled at the end of 1998 (including 23 trees with no pedigree and used as genetic controls) and two disks of wood of 20 and $10 \mathrm{~cm}$ thick, respectively, were obtained at $1.3 \mathrm{~m}$ above ground level from each of them. The first disk was used for assessing physical properties as well as radial growth, whereas the second one served for measuring chemical properties, including cellulose and lignin content. Geographical North was also marked on each wood disk, as a reference for further analyses.

Along the north radius of each $20 \mathrm{~cm}$ thick wood disk, a sub-sample $10 \mathrm{~mm}$ wide $\times 1.8 \mathrm{~mm}$ thick was obtained from pith to bark. This direction was chosen to minimize the presence of compression wood, since the prevailing winds were from the southwest.

\subsection{Wood properties assessment}

Wood samples were dried to equilibrium moisture of $12 \%$ and resins were extracted with a solution of ethanol. Intra-ring density information for each sample was obtained by using an indirect-reading X-ray densitometry system at the INRA Research Station of Orléans, France. The X-ray films of wood samples were digitized by using a scanner with a color resolution of eight bits (256 tones of gray) and a spatial resolution of $300 \mathrm{pixel} / \mathrm{inch}$. Each pixel covered a length of $0.085 \mathrm{~mm}$. The digitized images were processed by using the WinDENDRO software [14]. The initial raw data consisted of a density profile at the pixel level. Ring limits were also determined with the software and a careful visual observation of the actual wood samples. The last step in the data generation process used a computer routine written in $\mathrm{C}$ to measure the traits of interest.

The first and last annual rings were discharged from all samples because they were usually incomplete. This ensured the same statistical precision at all rings. Thus, only rings 2 to 14 were included in this research. The minimum (Dmin) and maximum (Dmax) density 
was measured in each ring. The mid density point (MDP) was calculated as half the difference between Dmin and Dmax (midway between the minimum and maximum densities of the ring) plus the minimum value:

$$
\mathrm{MDP}=\operatorname{Dmin}+\frac{(\mathrm{Dmax}-\mathrm{Dmin})}{2}=\frac{(\mathrm{Dmin}-\mathrm{Dmax})}{2} .
$$

The average ring density values lower and higher than the MDP were denoted as early- (ED) and latewood (LD) density, respectively. Distances from pith across rings $\mathrm{i}\left(\mathrm{d}_{\mathrm{i}}\right)$ and $\mathrm{i}-1\left(\mathrm{~d}_{\mathrm{i}-1}\right)$ were directly obtained from the X-ray density profiles and used to measure the overall ring area (RA) as $\pi\left(\mathrm{d}^{2}{ }_{\mathrm{i}}-\mathrm{d}^{2}{ }_{\mathrm{i}-1}\right)$. The areas lower and higher than the MDP were denoted as early- (EA) and latewood (LA) areas, respectively. The latewood proportion (LP) was estimated as the ratio between the ring area consisting of latewood and the total ring area. Cumulative late proportion (CLP) at cambial age $t$ was estimated as

$$
\mathrm{CLP}_{\mathrm{t}}=\frac{\sum_{i=2}^{t} \mathrm{LA}_{\mathrm{i}}}{\sum_{i=2}^{t} \mathrm{RA}_{\mathrm{i}}}
$$

where $\mathrm{LA}_{\mathrm{i}}$ and $\mathrm{RA}_{\mathrm{i}}$ were defined above. The measurement units were kilograms per cubic meter $\left(\mathrm{kg} / \mathrm{m}^{3}\right)$, for $\mathrm{ED}, \mathrm{LD}$, and squared centimeters $\left(\mathrm{cm}^{2}\right)$ for EA, LA, and RA.

\subsection{Linear mixed model and assumptions}

The mixed linear model used to represent the data obtained for a given trait and related to a particular ring was

$$
Y_{\mathrm{ijk}}=\mu+R_{\mathrm{i}}+f_{\mathrm{j}}+I_{\mathrm{ij}}+e_{\mathrm{ijk}}
$$

where $Y_{\mathrm{ijk}}$ is a phenotypic individual observation; $\mu$ is the overall mean; $R_{\mathrm{i}}$ is the fixed replication effect; $f_{\mathrm{j}}$ is the random family effect with mean zero and variance $\sigma_{\mathrm{f}}^{2} ; I_{\mathrm{ij}}$ is the random interaction or plot effect with mean zero and variance $\sigma_{\mathrm{I}}^{2}$; and $e_{\mathrm{ijk}}$ is the random residual effect with mean zero and variance $\sigma_{\mathrm{e}}^{2}$. Thus, $\mathrm{Y}_{\mathrm{ijk}}$ has mean $\mu+R_{\mathrm{i}}$ and the phenotypic variance was estimated as $\sigma_{\mathrm{P}}^{2}=\sigma_{\mathrm{f}}^{2}+\sigma_{\mathrm{I}}^{2}+\sigma_{\mathrm{e}}^{2}$. Families were considered to be full maternal half-sibs, and therefore the following relationship was assumed to estimate

$$
V_{\mathrm{AX}}=4 \sigma_{\mathrm{Fx}}^{2}
$$

where $V_{\mathrm{Ax}}$ and $\sigma_{\mathrm{Fx}}^{2}$ are the additive genetic variance and family variance component for trait $X$, respectively.

The final database was unbalanced due to the sampling scheme (1 to 2 healthy trees per plot). The normality of experimental data was checked using the SAS INSIGHT procedure [31]. Analyses of variance were conducted for all traits and cambial ages, and type III sums of squares were calculated by using the SAS GLM procedure [31]. The Satterthwaite's approximated test was used to measure the level of significance of family related effects [29]. Variance components for each trait and cambial age were estimated using the restricted maximum likelihood principle and the SAS MIXED procedure [20].

\subsection{Genetic and statistical analyses}

The narrow-sense individual tree heritability $\left(h^{2}\right)$ was calculated for each trait measured at the cambial age $t$ (ring number) as

$$
h^{2}=\frac{4 \sigma_{\mathrm{F}}^{2}}{\sigma_{\mathrm{P}}^{2}}
$$

where $\sigma_{\mathrm{F}}^{2}$ and $\sigma_{\mathrm{P}}^{2}$ are the family and phenotypic variance estimates, respectively.
Genetic correlations among different combinations of traits could not be estimated at several cambial ages because the family variance component of one trait was zero, as shown below in the figures depicting the trend of heritability changes with cambial age. To overcome this inconvenience, individual data were divided by the appropriate phenotypic standard deviation. This transformation of data removed the scale differences among traits and allowed reliable comparisons of family covariances among different traits. Covariance components, for each cambial age and transformed (standardized) traits, were also estimated using the restricted maximum likelihood principle and the SAS MIXED procedure [20]. It can be demonstrated that the family covariance component estimated with transformed data $\left(\operatorname{Cov}_{\mathrm{Fxy}}(\mathrm{std})\right)$ is equal to:

$$
\operatorname{Cov}_{\mathrm{Fxy}(\mathrm{std})}=\frac{\operatorname{Cov}_{\mathrm{Fxy}}}{\sigma_{\mathrm{Px}} \sigma_{\mathrm{Py}}}
$$

where $\operatorname{Cov}_{\mathrm{Fx} y}, \sigma_{\mathrm{Px}}$, and $\sigma_{\mathrm{Py}}$ are the family covariance component of the original non-transformed data and phenotypic standard deviations of the traits $X$ and $Y$, respectively. Thus, the new family covariance (transformed data) represents the contribution of the original family covariance (non-transformed data) to the real phenotypic correlation. A further analysis of the radial pattern of association among different traits was conducted by comparing the family covariance, based on transformed individual data, with the corresponding phenotypic correlation, which was estimated as

$$
r_{\mathrm{Pxy}}=\frac{\operatorname{Cov}_{\mathrm{Pxy}}}{\left(\sigma_{\mathrm{Px}}^{2} \sigma_{\mathrm{Py}}^{2}\right)^{1 / 2}}
$$

where $\operatorname{Cov}_{\mathrm{Pxy}}$ is the phenotypic covariance between traits $X$ and $Y$, and was calculated as $\operatorname{Cov}_{\mathrm{Pxy}}=\operatorname{Cov}_{\mathrm{Fxy}}+\operatorname{Cov}_{\mathrm{Ixy}}+\operatorname{Cov}_{\mathrm{exy}}$, i.e. as the sum of the family, interaction, and residual covariance components, respectively. It can also be demonstrated that the phenotypic correlation, $r_{\mathrm{Pxy}}$, is equal to $\operatorname{Cov}_{\mathrm{Fxy}(\mathrm{std})}+\operatorname{Cov}_{\mathrm{Ixy}(\mathrm{std})}+\mathrm{Cov}_{\mathrm{exy}(\mathrm{std})}$, i.e. to the sum of the family, interaction, and residual covariance components respectively, estimated with transformed data. Here, we are also assuming the following relationship:

$$
\operatorname{Cov}\left(A_{\mathrm{x}}, A_{\mathrm{y}}\right)=4 \operatorname{Cov}_{\mathrm{Fxy}}
$$

where $\operatorname{Cov}\left(A_{\mathrm{x}}, A_{\mathrm{y}}\right)$ and $\operatorname{Cov}_{\mathrm{Fxy}}$ are the additive genetic covariance and family covariance component between traits $X$ and $Y$, respectively.

Approximate standard errors of heritability and new family covariance estimates were calculated by using the asymptotic large-sample dispersion matrix associated to the REML method [32], and the Taylor series expansion analysis [21].

\section{RESULTS AND DISCUSSION}

\subsection{Variation of family means with cambial age}

Family mean values for ED increased with cambial age for all families (Fig. 1A). The same trend was observed for average ring density reported in our previous paper. All families also followed the same pattern of LD with cambial age (Fig. 1B).

Several studies reported that some coniferous species show a tendency to increase values of ring density components outward from the pith [10]. For example, Vargas-Hernandez [34] observed that area weighted ED and LD increased with cambial age in 60 families of coastal Douglas-fir that were analyzed at age 15. A similar pattern was reported by Wang [36], who studied families of lodgepole pine and also observed that LD was initially low but increased during the first years, reached its 


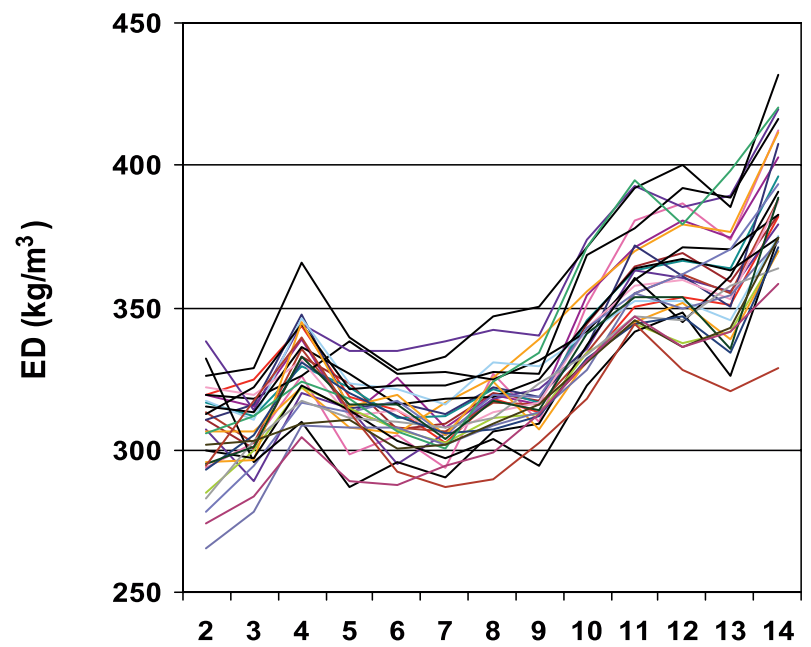

(A) Ring number from pith

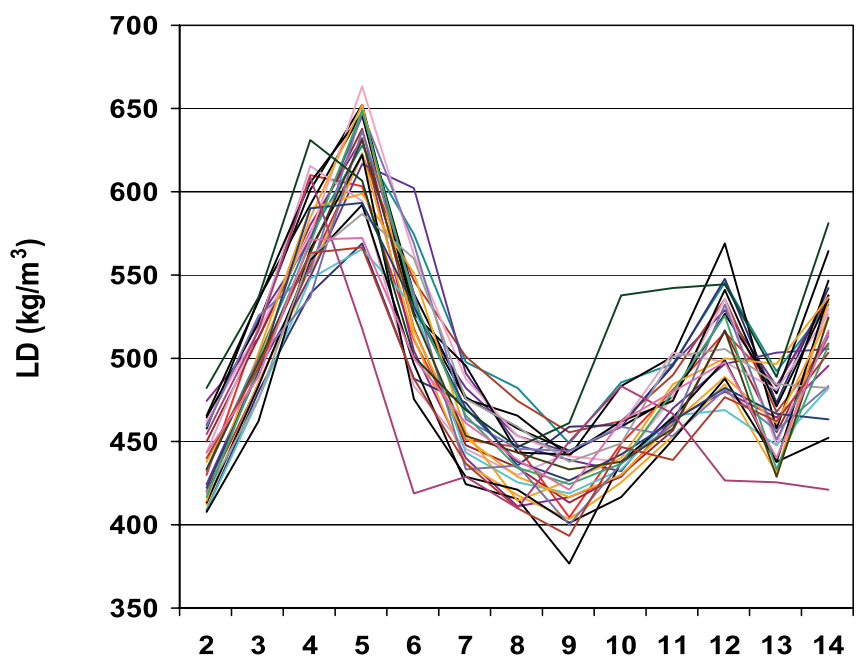

(B) Ring number from pith

Figure 1. Changes in family mean values for within ring density components with cambial age. (A) ED; (B) LD.

maximum at age 6, and then started to decline. Megraw [22] also found for loblolly pine that latewood specific gravity increases rapidly with ring number from the pith until values reach a characteristic high level, at around ring 5. The same pattern of changes in latewood density was also mentioned by Zobel and Sprague [42] for other conifers. These authors added that earlywood density tends to change less from pith to bark. In contrast Hylen [18] studied Norway spruce and found that average values of ED and LD decreased over the first few rings from the pith and reached their lowest values at different rings. Nicholls [26] also discussed the presence of different patterns of changes in ring density from pith outwards in radiata pine. In his study, he mentioned that density generally increased from the pith outwards. But he also reported that some radiata pine trees exhibited an initial decrease in density in the first few rings before it started to increase outwards.
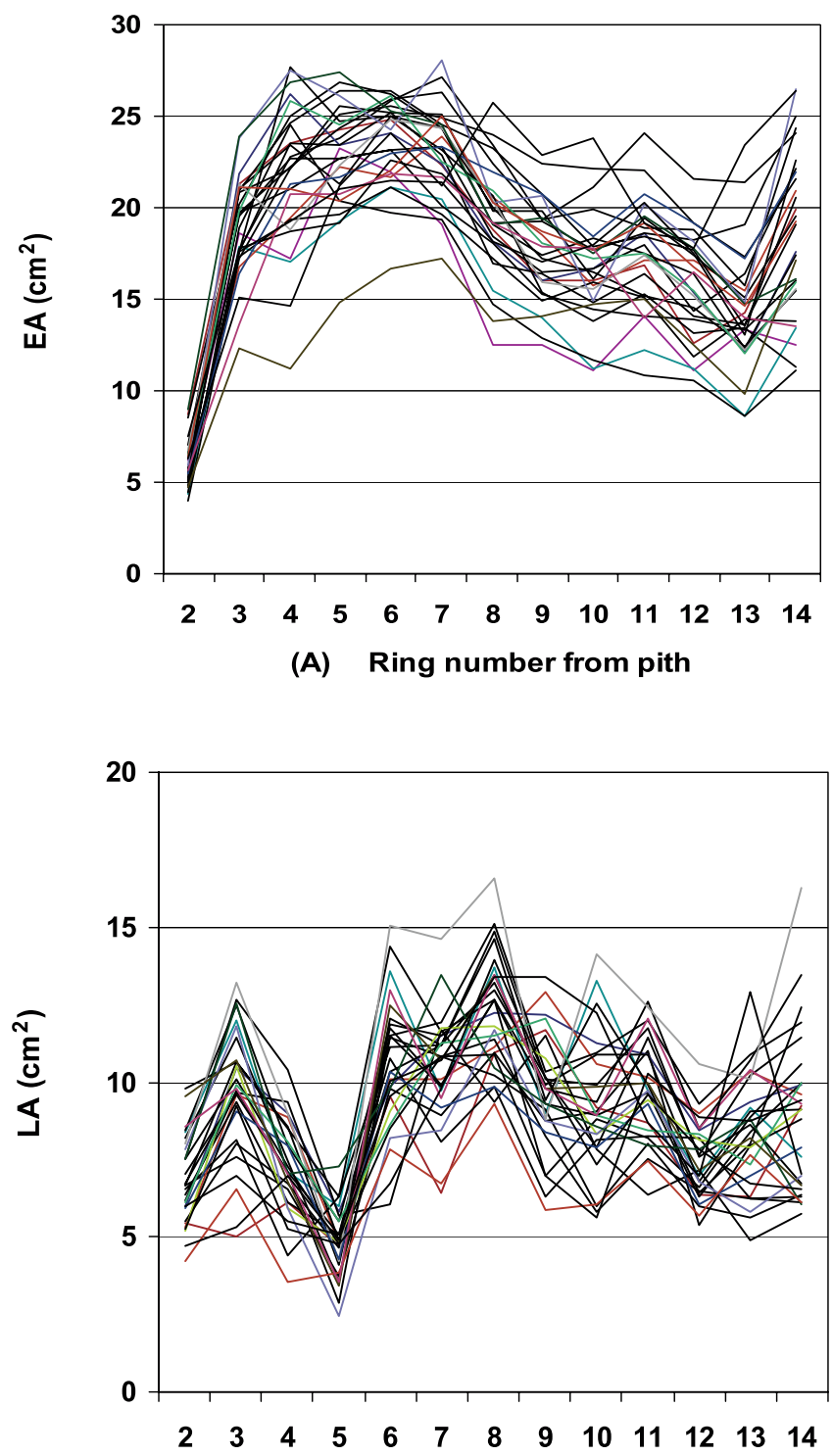

(B) Ring number from pith

Figure 2. Changes in family mean values for within ring area components with cambial age. (A) EA; (B) LA.

All family mean values for EA increased after ring 2 and reached a plateau between rings 4 and 7 . After ring 7, family average tended to decrease (Fig. 2A). The same trend was also observed for the total ring area as reported in our previous paper [38]. All families showed the same fluctuating pattern of changes for LA between rings 2 and 6 (Fig. 2B). The drastic decrease in family mean LA at ring 5 , recorded in all progenies, is in direct relationship with the increment in LD observed at the same ring (Fig. 1B).

Most of the family averages for LP decreased from ring 2 to a minimum at ring 5 (see Fig. 3A). After ring 6, mean values fluctuated erratically outwards to the bark. Family means for CLP also decreased from ring 2 towards ring 5 (Fig. 3B), but after ring 7 values asymptotically approached around $35 \%$, for all families. 


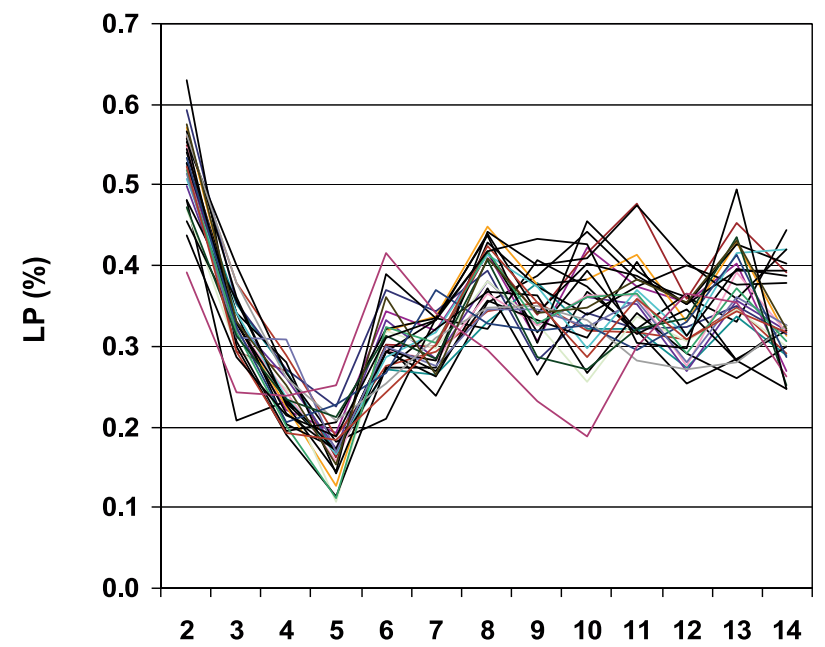

(A) Ring number from pith

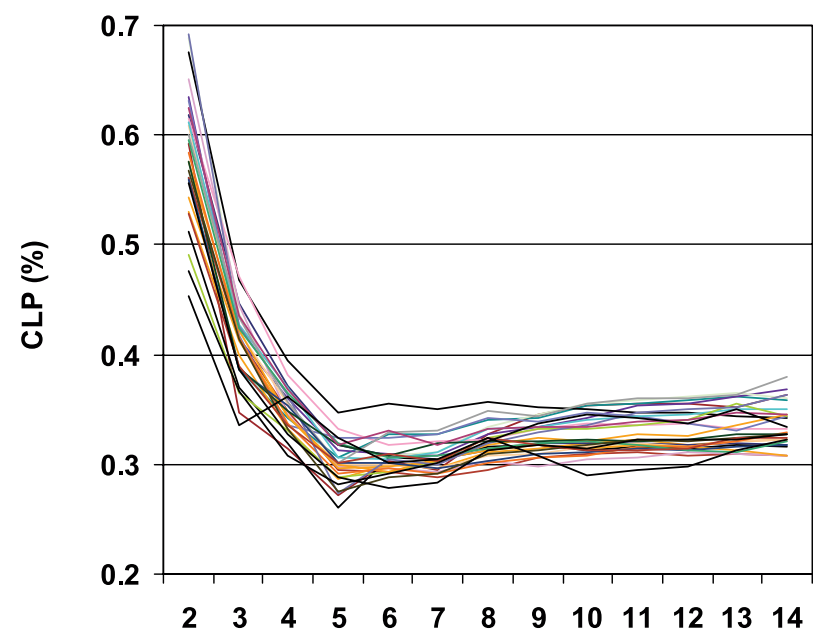

(B) Ring number from pith

Figure 3. Changes in family mean values for latewood proportion with cambial age. (A) LP; (B) CLP.

Wang [36] studied lodgepole pine and also recorded that LP was high in the early rings, but declined sharply thereafter. In Douglas-fir, Vargas-Hernandez [34] also observed a decreasing but irregular trend in LP in early cambial age, and then a steady increase after ring 11 . A contrasting result was observed by Hylen [18] in a young Norway spruce progeny test where the LP increased steadily with increasing ring number, for individual ring and cumulative values. Gantz [13] also reported mean latewood percentages ranging between $38 \%$ and $45 \%$ for 10 -year-old radiata pine trees growing on three different sites in Chile.

Latewood and earlywood amounts are difficult to measure since there is a transition zone between them. The two types of woods are especially difficult to assess in the low-density conifers, the soft pines, and the diffuse-porous hardwoods [41]. Different researchers can obtain different percentages when measuring the same cross section of wood, depending on the individual's opinion or method used to determine where earlywood stops and latewood starts. Though its accurate assessment is not easy, latewood percent can be used to categorize wood into broad groups [42]. According to Van Buijtenen [33], the percent of latewood has by far the largest influence on wood specific gravity. Zobel and Jett [41] mention that latewood percent is usually referred as the ratio of latewood to earlywood. In our research, we estimated latewood proportion using the definition of Vargas-Hernandez [34] and Hylen [18], which is based on the area of the ring occupied by the latewood.

Earlywood is characterized by lower density, larger lumens, and thinner cell walls than latewood [16], and to some extent by a greater cell size [41]. As a result, earlywood pulps are very different from those made from latewood [42]. Watson and Dadswell [37] reported that pulps of loblolly pine containing $20-50 \%$ of latewood fibers had a good tearing strength while retaining acceptable levels for bursting and tensile strength. They also mention that the proportion of latewood for radiata pine was less than $20 \%$, which would not have any marked influence on papermaking properties. Zonel and Jett [41] reported that the proportion of latewood in radiata pine is less than $50 \%$. Harris [15] stated that this percentage is about $20 \%$. Our results show that the cumulative latewood proportion (CLP) approached a steady value around $35 \%$ with increasing cambial age.

\subsection{Family differences and changes in genetic control}

Family differences in ED (Fig. 4A) were only significant near the pith (rings 2 to 4 ) and near the bark (rings 11 to 14). Heritability for ED dropped from 0.43 at ring 2 to less than 0.2 , between rings 5 to 10 , reflecting low genetic variation (Fig. 5A). The maximum value was 0.51 and was recorded at ring 12 . Also the precision of the heritability estimate is low between rings 5 to 11 . In our previous paper, we studied the pattern of average ring density (ARD) of the whole ring and this trait followed the same trend as ED.

The highest heritability for LD was also recorded at ring 2 (0.35). No genetic variation was observed at rings 11 and 13 . Heritability followed an oscillating pattern with cambial age (Fig. 5B). The highest family differences in LD (Fig. 4A) were also observed at rings 2 and 10 .

In radiata pine, Nicholls [24] also reported a systematic change in heritability with cambial age for wood density. He observed that heritability of basic density in radiata pine decreased from the pith outward until a minimum reached around ring 9, followed by an increase in heritability with further increase in age. In a following paper [25], the same author states that the genetic control of this trait appears to reach a maximum early in the life of trees and therefore maximum gains from selection can be obtained in the first-formed wood. In a 23 year-old radiata pine progeny test established in New South Wales, Australia, Nyakuengama [28] found that narrow sense heritabilities of latewood density initially decreased from the pith until ring 12 and then increased until ring 18, while earlywood density followed an oscillating pattern of variation. In their study of families of radiata pine established in several sites in New Zealand, Cown and Ball [8] also measured average ring density and determined that heritability of wood density in the 

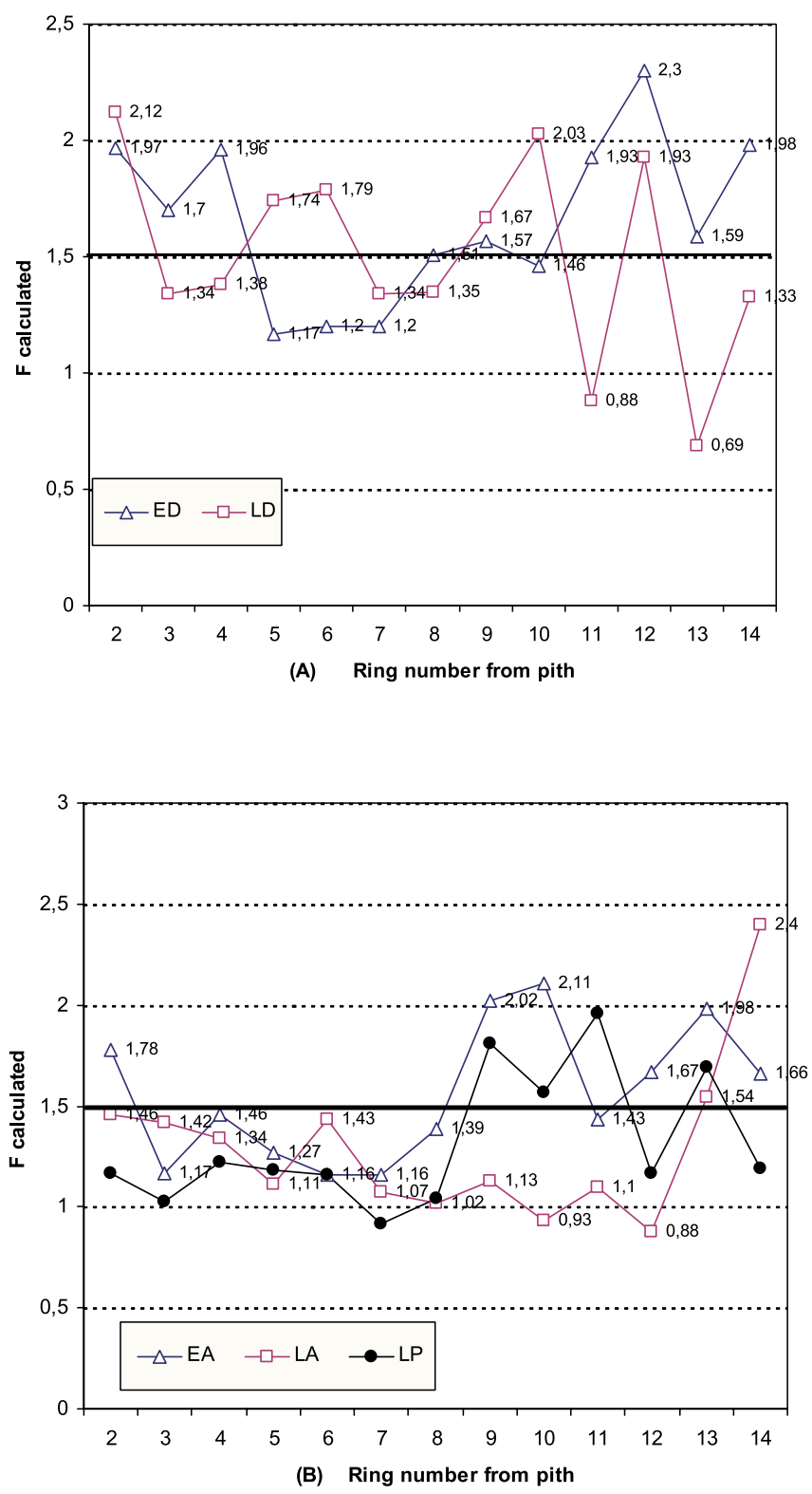

Figure 4. Results from approximated $F$-tests for ring area and density components. Significant differences among families are showed when $F$-values are above the continuous line representing $F=1.56$, and $P<0.05$. (A) ED and LD; (B) EA, LA and LP.

juvenile (rings 1 to 10) and mature (rings 11 and more) wood sections were 0.62 and 0.68 , respectively.

Zobel and Jett [41] stressed that for other species, such as loblolly pine, heritability of wood density has a clear tendency to increase with cambial age. In a study conducted in slash pine (Pinus elliottii), Hodge and Purnell [16] observed moderate heritability values for density $\left(h^{2} \geq 0.2\right)$ close to the pith (rings 3 and 4 ) and in mature wood (rings 11 and 13). Intermediate rings showed slightly lower heritabilities $\left(h^{2}=0.1-0.15\right)$.

In our study, heritability tended to increase with cambial age for EA (Fig. 5C). Additive genetic variation was low $\left(h^{2}<0.2\right)$ before ring 8. Between rings 9 and 14, genetic control was moderate with heritability ranging from 0.21 at ring 11 to 0.43 at ring 13.

Family differences in LA (Fig. 4B) were significant only at ring 14, also location of the highest heritability estimate for this trait (Fig. 5D). In general, LA was under low genetic control at most cambial ages $\left(h^{2} \leq 0.25\right)$.

Genetic control for LP was negligible $\left(h^{2} \leq 0.15\right)$ before ring 9 and 12 (Fig. 5E). Additive genetic variation was moderate $\left(h^{2}>\right.$ 0.25 ) only at rings 11 and 13 . Except for rings 12 and 14, family differences in LP (Fig. 5B) were mainly significant after ring 8 . In contrast with these results, Hodge and Purnell [16] observed heritability values for LP of 0.12-0.13 near the pith (rings 3 and 4) and close to zero for intermediate and later rings. In our case, there is little additive variance for LP in juvenile wood and all trees produced the same percentage of earlywood (Figs. 3A and $5 \mathrm{E})$.

The heritability estimates reported here should be viewed in relative terms. The wood analysis was based on samples from only one location and environmental effects have changed as the stand matured. Therefore, heritability values may be biased upward because of inadequate environmental sampling [23]. If heritability is estimated on a single site, the family $\times$ environment interaction variance cannot be assessed and is added to the estimate of family variance on that particular site. Thus, the single-site heritability is biased because it estimates the sum of additive plus additive $\times$ environment variance relative to the total phenotypic variance [17].

\subsection{Changes in family covariation and phenotypic correlation between density components}

The family covariance between ED and LD tended to decrease with cambial age and was negative at rings 8 and 10 (Fig. 6A), which are in the transition region between juvenile and mature wood. Contrarily, the phenotypic correlation between both traits tended to increase with cambial age, particularly after ring 5 (Fig. 7A). In general, the family covariance reflected a low contribution to the phenotypic correlation between ED and LD across cambial ages.

The family covariance between ED and EA was negative at age 2 and positive between ages 3 and 7, which is mainly juvenile wood (Fig. 6B). This covariance decreased with cambial age after ring 5 and was negative between cambial ages 10 and 14. These results indicate a positive genetic relationship between ED and EA in the wood close to the pith shifting to a negative relationship towards the region formed by mature wood. The phenotypic correlation between ED and EA was positive only between rings 5 and 7 (Fig. 7B), but weak $(<0.1)$. This correlation became more negative towards the pith and the bark. It seems that non-genetic factors had more important influences on both traits in mature wood (where $|0.1|<r_{\text {Pxy }}$ ).

From rings 3 to 7, family covariance between LD and LA was lower than between ED and EA (Fig. 6B). This relationship was reversed from rings 9 to 13 . Eight of the 13 rings showed a negative covariance. The phenotypic correlation between LD and LA was negative in 13 rings (Fig. 7B) and more negative again between ED and EA in 10 rings. It is evident that for most cambial ages, regardless of the type of wood formed (early or 

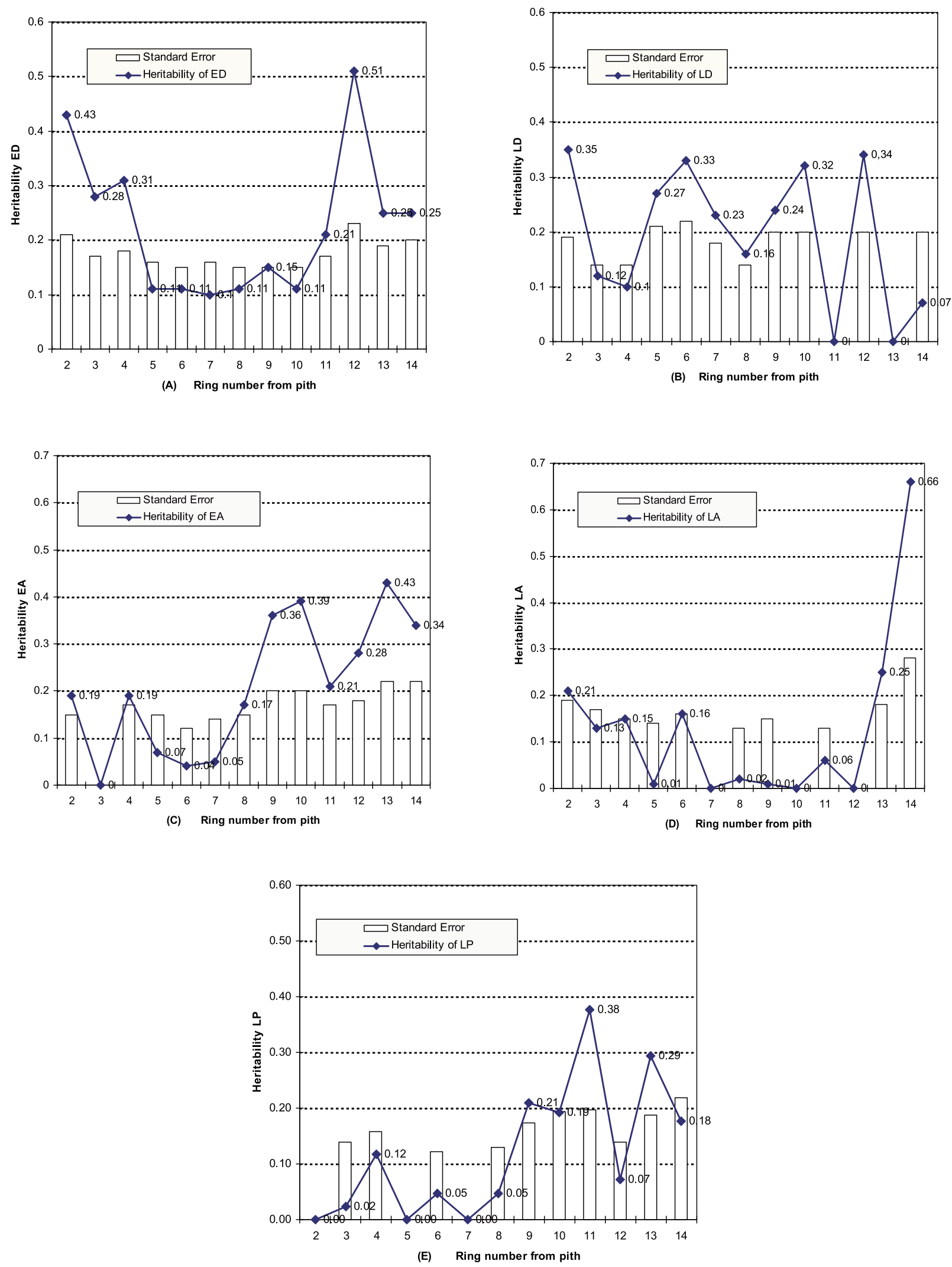

Figure 5. Age trends in individual tree heritability $\left(h^{2}\right)$ and standard errors (SE) for (A): ED, (B): LD, (C): EA, (D): LA, and (E): LP, at different ring numbers counted from the pith. 

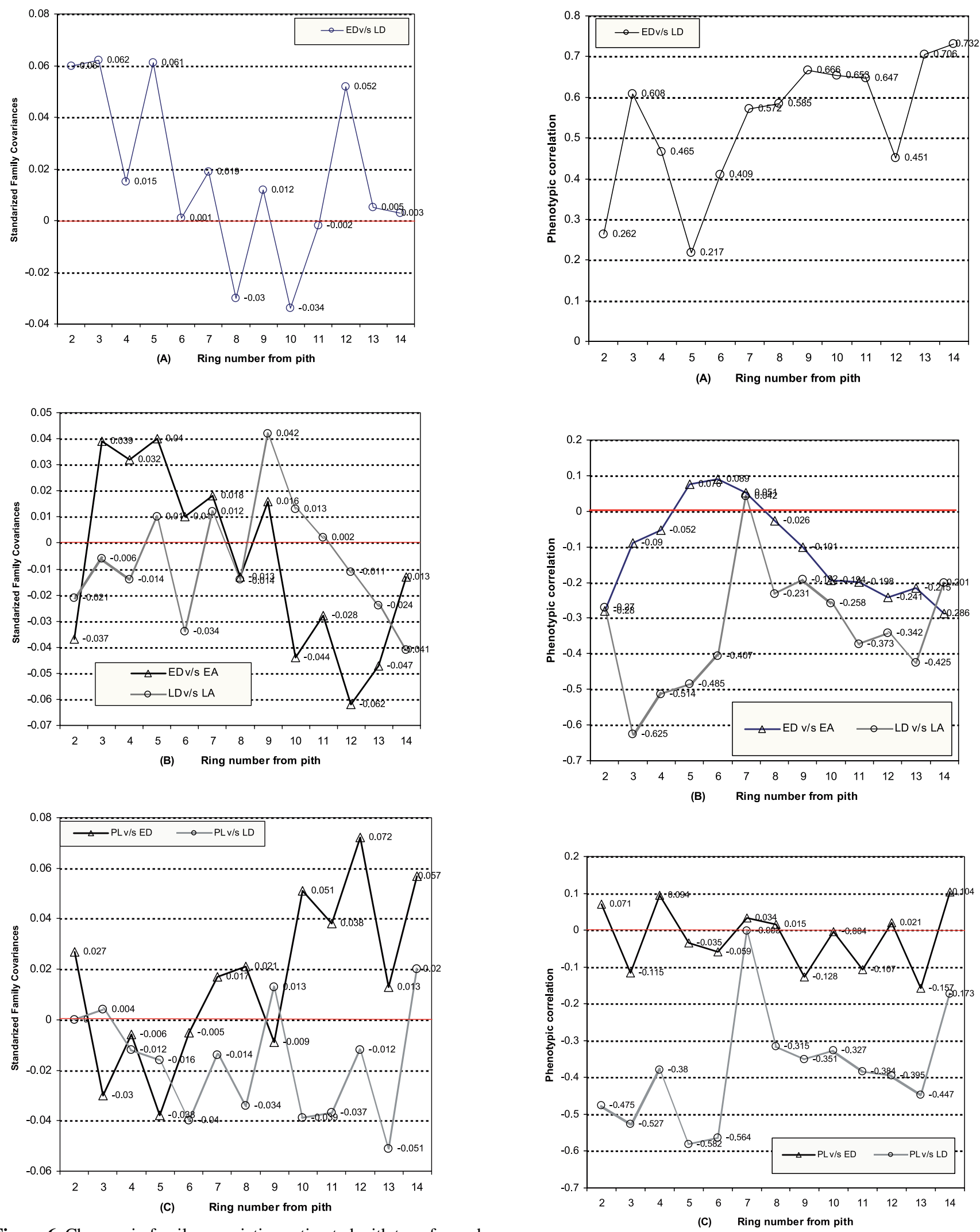

Figure 6. Changes in family covariation estimated with transformed data, which is the contribution of the original family covariation (nontransformed data) to the phenotypic correlation: (A) ED v/s LD, (B) ED v/s EA and LD v/s LA, and (C) PL v/s ED and PL v/s LD.

Figure 7. Changes in phenotypic correlation with cambial age: (A) ED v/s LD; (B) ED v/s EA, and LD v/ LA; and (C) PL v/s ED and PL v/s LD. 
latewood), an increment in LD is related to a decrease in the corresponding area. Our results show that the genetic relationship between both traits is negative but weak before ring 5 (juvenile wood) and after ring 10 (mature wood).

The relationships between wood density components and growth rate are of great importance. Few references are available describing changes with cambial age in radiata pine. Cown [9] summarized several studies regarding the effect of growth rate on the density of radiata pine, saying that there is no clear correlation between growth rate and density, though Bannister and Vine [1] found a weak negative phenotypic correlation between both traits. Cown [9] added that tree age, not tree growth rate, was the determining factor for wood density in all site conditions studied. Nicholls et al. [27] also reported a small, non-significant genetic correlation between ring width and average density and the presence of a small negative correlation that tended to disappear in older growth rings, which agrees with results presented by Zamudio et al. [38]. In contrast, Burdon and Young [4] recorded a strong negative correlation between wood density and growth rate in rings 6 to 10, a weaker correlation in rings 10 to 20, and no correlation in rings 0 to 5 . Our results suggest a weak positive genetic correlation between earlywood density and its area in juvenile wood, and an increasingly negative correlation between these traits towards the mature wood.

Strong to moderate negative genetic relationships between diameter growth rate and wood density have been reported in several species, such as Picea abies [41], Picea glauca [5] and Pseudotsuga menziesii [3, 19, 35]. Zhang et al. [39] studied black spruce progenies growing in two sites and observed that higher growth rate resulted in lower latewood percent and lower wood density. They also suggested that latewood density was significantly less related to latewood width than earlywood density with earlywood width.

Family covariance between ED and PL was positive at rings 2, 7, 8 and after ring 9 (Fig. 6C) with a trend to increase with cambial age. Family covariance between PL and LD was negligible at rings 2 and 3 and positive only at rings 9 and 14. The phenotypic correlation between ED and PL is very weak, regardless of the cambial age (eight values were $<10.11$ ). The phenotypic correlation between LD and PL was zero at ring 7 and negative at the others cambial ages, with 11 correlations in the range $-0.6<r_{\mathrm{P}}<-0.3$ (Fig. 7C). This means that an increment in latewood density conducts to an evident but moderate decrease in latewood proportion. Considering the magnitude of the phenotypic correlation, we think that the relationship between LD and PL is mainly due to non-genetic effects.

\subsection{Environmental effects on wood density components}

Yearly variations in climatic conditions like the decrease in the precipitation rate from 1986 to 1990 could have produced the pattern of changes in mean ED and LD observed in Figures 1A and 1B, although the environmental effect was more pronounced on LD than on ED. For example, all families follow the same highly significant increment in average LD recorded at age 5. A similar but smaller increment in mean ED was also observed in all families at age 4. Most authors agree that the latewood component is the most sensitive to environmental influences [7, 8]. Harris [15] found that LD in radiata pine in New Zealand was closely correlated with mean annual temperature $(r=0.94)$. In southern pines, Clark and Saucier [6] stated that juvenile wood patterns were related to the length of the growing season and to the rainfall patterns. Cregg et al. [11] showed that the date of transition from earlywood to latewood was earlier in dryer summer.

The erratic pattern of genetic control followed by LD is another indication that this trait is more susceptible to environmental effects than ED and average ring density. Thus, its improvement should also be more sensitive to silviculture than to genetic manipulation. Potential factor of the environment affecting the trait is water availability in the soil, which is generally closely related to precipitation, temperature and photoperiod. In Chile, radiata pine is planted in areas ranging from mediterranean to temperate climate, with very variable number of months with precipitation during the growing season.

\section{CONCLUSIONS}

Our results suggest that any selection effort to modify the homogeneity of wood density within the stem will have a more direct impact on ED than LD. ED showed significant genetic variation in juvenile wood region and after ring 11, thus breeding for increasing ED in both regions is feasible.

From pith to bark phenotypic variation in density components can be interpreted as plasticity, while genetic variation in the same density components can be interpreted as an adaptive response to specific environmental conditions (here a sandy soil, an average precipitation rate of $1100 \mathrm{~mm}^{-1} \mathrm{year}^{-1}$ and a drought period close to 5 months [38]). Next step will be to determine whether the same pattern of changes in phenotypic traits and in genetic parameters with cambial age is observed or not in other progenies established in different test sites, under similar or different environmental conditions. Results will contribute to better understanding the consequences on wood quantity and wood quality of the observed plastic and adaptive response of radiate pine to varying environments in Chile.

Acknowledgments: Research was funded by the Chilean National Science and Technology Commission (CONICYT), grant FONDECYT No. 1980049. Support came also from the ECOS-CONICYT grant No. C97B04. The authors are also grateful to Forestal Mininco S.A. for its technical support in the field, for providing the database, and for allowing publishing of the results of this study. The field experiment complies with the current Chilean laws regarding safety and environmental issues.

\section{REFERENCES}

[1] Bannister M.H., Vine M.H., An early progeny trial in Pinus radiata. 4. Wood density, N.Z. J. For. Sci. 11 (1981) 221-243.

[2] Barefoot A.C., Hitchings R.G., Ellwood E.L., Wilson E., The relationship between loblolly pine fiber morphology and kraft paper properties, Bull. NC Agr. Exp. Stn. Tech. Bull. 202 NC State Univ. Raleigh, NC, 1970, 88 p.

[3] Bastien J.C., Roman-Amat B., Vonnet G., Natural variability of some wood quality traits in coastal Douglas-fir in a French progeny test: implications on breeding strategy, in: Ruetz W., Nather J. (Eds.), Proceedings, IUFRO Working Party on Breeding Strategies 
for Douglas-fir as an Introduced Species, June 1985, Vienna, Austria, 1985, 21, pp. 169-186.

[4] Burdon R.D., Young G.D., Some wood properties in four Pinus radiata provenances at Kaingaroa Forest, rings 1-20 from pithpilot results, in: Proc. 11th Meeting Representative Research Working Group No. 1 (Forest Genetics) Australian For. Council Coonawarra, South Australia, 1991, pp. 141-143.

[5] Carriveau A., Beaulieu J., Mothe F., Wood density of natural white spruce populations in Quebec, Can. J. For. Res. 17 (1987) 675-682.

[6] Clark A., Saucier J.R., Influence of planting density, intensive culture, geographic location, and species on juvenile wood formation in southern pine, Georgia For. Res. Pap. 85, Georgia For. Comm. 1991, $13 \mathrm{p}$.

[7] Cown D.J., Corewood (juvenile wood) in Pinus radiata - should we be concerned? N.Z. J. For. Sci. 22 (1992) 87-95.

[8] Cown D.J., Ball R.D., Wood densitometry of 10 Pinus radiata families at seven contrasting sites: Influence of tree age, site, and genotype, N.Z. J. For. Sci. 31 (2001) 88-100.

[9] Cown D.J., McConchie D.L., Young G.D., Radiata pine-wood properties survey, FRI Bull. No. 50, Rotorua, New Zealand, 1991, 50 p.

[10] Cown D.J., Parker M.L., Densitometric analysis of wood from five Douglas-fir provenances, Silvae Genet. 28 (1979) 48-53.

[11] Cregg B.M., Dougherty P.M., Hennessey T.C., Growth and wood quality of young loblolly pine trees in relation to stand density and climatic factors, Can. J. For. Res. 18 (1988) 851-858.

[12] Einspahr D.W., van Buijtenen J.P., Peckham J.R., Pulping characteristics of ten years old loblolly pine selected for extreme wood specific gravity, Silvae Genet. 18 (1969) 57-61.

[13] Gantz C.H., Evaluating the efficiency of the resistograph to estimate genetic parameters for wood density in two softwood and two hardwood species, M.S. thesis, College of Natural Resources, North Carolina State University, 2002, 88 p.

[14] Guay R., Gagnon R., Morin H., A new automatic and interactive tree ring measurement system based on a line scan camera, Forest. Chron. 68 (1992) 138-141.

[15] Harris J.M., Specific gravity and summerwood percent, N.Z. For. Serv. For. Res. Inst. FRI Rotorua, N.Z. Symp., 1966, pp. 34-36.

[16] Hodge G.R., Purnell R.C., Genetic parameter estimates for wood density, transition age, and radial growth in slash pine, Can. J. For. Res. 23 (1993) 1881-1891.

[17] Hodge G.R., White T.L., Genetic parameter estimates for growth traits at different ages in slash pine and some implications for breeding, Silvae Genet. 41 (1992) 252-262.

[18] Hylen G., Age trends in genetic parameters of wood density in young Norway spruce, Can. J. For. Res. 29 (1999) 135-143.

[19] King J.N., Yeh F.C., Heaman J.Ch., Dancik B.P., Selection of wood density and diameter in controlled crosses of coastal Douglas-fir, Silvae Genet. 37 (1988) 152-157.

[20] Littell R.C., Milliken G.A., Stroup W.W., Wolfinger R.D., SAS ${ }^{\circledR}$ System for Mixed Models, Cary, NC: SAS Institute Inc., 1996, $633 \mathrm{p}$.

[21] Lynch M., Walsh B., Genetics and analysis of quantitative traits, Sinauer Associates, Inc. MA., 1998, 980 p.

[22] Megraw R.A., Wood quality factors in loblolly pine, TAPPI Press, Atlanta, GA, 1985, $89 \mathrm{p}$
[23] Namkoong G., Barefoot A.C., Hitchings R.G., Evaluating control of wood quality through breeding, Tappi 52 (1969) 1933-1938.

[24] Nicholls J.W., Preliminary observations on the change with age of the heritability of certain wood characteristics in Pinus radiata clones, Silvae Genet. 16 (1965) 18-20.

[25] Nicholls J.W., Assesment of wood quality for tree breeding. IV. Pinus pinaster grown in western Australia, Silvae Genet. 16 (1967) 21-28.

[26] Nicholls J.W., Within-tree variation in wood characteristics of Pinus radiata D. Don, Aust. For. Res. 16 (1986) 313-335.

[27] Nicholls J.W., Morris J.D., Pederick L.A., Heritability estimates of density characteristics in juvenile radiata wood, Silvae Genet. 29 (1980) 54-61.

[28] Nyakuengama J.G., Matheson C., Evans R., Spencer D., Vinden P., Effect of age on genetic control of Pinus radiata earlywood and latewood properties, APPITA J. 53 (1999) 103-107.

[29] Rawlings J.O., Pantula S.G., Dickey D.A., Applied regression analysis. A research tool, 2nd ed., Springer-Verlag, 1998, 657 p.

[30] Ridoutt B.G., Sorensson Ch.T., Lausberg M.J.F., Wood properties of twenty highly ranked radiata pine seed production parents selected for growth and form, Wood Fiber Sci. 32 (1998) 128-137.

[31] SAS Institute Inc., SAS/STAT ${ }^{\circledR}$ Software: Changes and Enhancements through Release 6.12, Cary, NC SAS Institute Inc., 1997, $1167 \mathrm{p}$.

[32] Searle S.R., Casella G., McCulloch C.E., Variance components, John Wiley \& Sons, New York, 1992, 501 p.

[33] Van Buijtenen J.P., Anatomical factors influencing wood specifics gravity of slash pines and the implications for the development of high-quality pulpwood, Tappi 47 (1964) 401-404.

[34] Vargas-Hernandez J., Adams W.T., Krahmer R., Family variation in age trends of wood density traits in young Coastal Douglas-fir, Wood Fiber Sci. 26 (1994) 229-236.

[35] Vargas-Hernandez J., Adams W.T., Genetic variation of wood density components in young coastal Douglas-fir implications for tree breeding, Can J. For. Res 21 (1991) 1801-1807.

[36] Wang T., Aitken S., Rozenberg P., Millie F., Selection for improved growth and wood density in lodgepole pine: Effects on radial patterns of wood variation, Wood Fiber Sci. 32 (2000) 391-403.

[37] Watson A.J., Dadswell H.E., Influence of fibre morphology on paper properties. Part II. Earlywood and Latewood, APPITA 15 (1962) 116-129.

[38] Zamudio F., Baettig R., Vergara A., Guerra F., Rozenberg P., Genetic trends in wood density and radial growth with cambial age in a radiata pine progeny test, Ann. For. Sci. 59 (2002) 541-549.

[39] Zhang S.Y., Simpson D., Morgenstern E.K., Variation in the relationship of wood density with growth in 40 black spruce (Picea mariana) families grown in New Brunswick, Wood Fiber Sci. 28 (1996) 91-99.

[40] Zobel B.J., Van Buijtenen J.P., Wood variation, its causes and control, Springer, Berlin, Heidelberg, and New York, 1989, 367 p.

[41] Zobel B.J., Jett J.B., Genetic if wood production, Springer, Berlin, Heidelberg, and New York, 1995, 367 p.

[42] Zobel B.J., Sprague J.R., Juvenile wood in forest trees, Springer, Berlin, Heidelberg, and New York, 1998, 300 p. 